\title{
ENERGY FOR BUILDINGS
}

\author{
Guest Editor \\ Vytautas MARTINAITIS \\ Department of Heating and Ventilation, \\ Vilnius Gediminas Technical University
}




\title{
Editorial
}

\section{ENERGY FOR BUILDINGS}

\author{
Guest Editor: Vytautas Martinaitis
}

\author{
Department of Heating and Ventilation, Vilnius Gediminas Technical University, \\ Sauletekio al.11,LT-10223 Vilnius,Lithuania.E-mail: sok@ap.vtu.lt
}

This special issue of the Journal has been compiled from the selected, expanded and revised versions of the $6^{\text {th }}$ International Conference "Energy for Buildings" proceedings (Vilnius, Oct 7-8, 2004). The conference was organised by the initiative of the Dept of Heating and Ventilation of Vilnius Gediminas Technical University as a traditional continued VGTU scientific informational event. It took place under the umbrella of REHVA's (Federation of European Heating and Air-conditioning Associations) the $47^{\text {th }}$ General Assembly. In the conference more than 70 presentations from 16 countries were introduced.

Life cycle analysis of a building (as energy consuming technical system) has shown that building service systems consume the biggest part of a supplied energy, especially in cooler climate countries. It seems obvious that the process inflicts some economical and environmental consequences. Solving problems related to systems efficiency issues and employing systematic approach, there naturally arise questions concerning technological processes and systems performance, operation and maintenance management, evaluation criteria and necessity of energy process integration in buildings. Taking into consideration the building process stages and construction components variety, it could be desired to see a number of combinations of integrated solutions - starting with technologicalmanagement features, which incorporate architectural design and building process integrity, and finishing with the integrity of technological systems and processes. The building services (internal systems, HVAC, plants, energy supply etc) are worth about $2 \%$ of GDP and are essential for an efficient operation of buildings. Building services account for over $50 \%$ of the capital costs. The scale and importance of this phenomenon witness that in the European Union the greatest part of energy is consumed in building sector. The effective buildings envelope isolation method has nearly reached its end. Integrated solutions for building service systems still have not exploited the potential, which could offer contemporary energy process transformation technologies and research methods. These methods formed by thermodynamics have passed and now continue the "E" chain (Energy, Entropy, Exergy, Emergy), which is more closely linked with economics, ecology and environment. From the point of a global view, a part of works on this issue complements still spare, but rapidly expanding the research and knowledge fund in this field, especially linked with building service systems.

The expensive from the standpoint of investments and operation the energy, heat production and supply systems; processes were and still are an object of constant research. But the focus is changing. The works, allocated for cogeneration and optimal updating the present networks, are important both by their topicality and general scientific value. The research of small-scale co-generation employed in public buildings are newsworthy by its assumed logical frame and obtainable results. The statement is confirmed and developed that the more the co-generator approaches the consumer, the more rigorous analysis of its work regime and necessary load is to be performed. In the Eastern Europe the questions of conservation and renovation of present district heating will remain relevant and topical in a long time. In order to search for rational decisions the mathematical models are established by invoking the sustained and inte- grated resources planning principles that better reflect the public interests. The attitude of the research presented in the publication allows to plan the district heating modernisation with an appropriate assessment of end users' facilities renovation and district heating depreciation, to discover the rational combinations of piping and users substations renovation. Taking into account the real heat consumption and load demand, consumed kinds of fuel and closing up of Ignalina nuclear power plant, these principles enable to come with the necessity to install load and structure of co-generator. Analysis on the basis of district heating monitoring by neural networks gives the evidence that it is needed and possible to find optimal and technologically reasonable monitoring stations and expensive equipment installed there while selecting the modern district heating control systems.

Head demand for buildings, building energy efficiency mostly depend on the envelope characteristics. The lately dispersed metering data of building heat expenditures do not always support the reliability of the applied calculations. Otherwise, the new materials, technologies of construction and energy generation and especially the technologies of process control demand a more exact assessment of unrolling processes of heat and mass exchange in the buildings considering the year seasons and alternating regime of energy demand during a day.

Heat consumption of similar buildings under the same climatic conditions normally shows different values. Uncertainty analysis is an appropriate way to provide a more comprehensive information on heat use for heating; it particularly allows evaluating the dispersion in heat consumption of similar residential houses, or this is due the design faults and violations of the building standards.

As the concept of building services system warranting a desirable behaviour of indoor thermal microclimate and energy use, even with modern enough control systems, a great demand is for an accurate methodology for calculating the non-steady state heat transfer. Thermal receptivity calculation methodology and common engineering method are analysed for the lightweight, heterogeneous and low thermal inertia envelopes of buildings under summer conditions. Rightly valued heat inflows in the non-steady building volume energy balance calculations condition the savings of energy use by protection from overheating and in the intermittent heating case to find appropriate installed power and preheating time.

Artificial neural networks are widely used in system modelling and the neural networks are considered as universal function approximation. The infiltration process, the measurements and analysis of air infiltration through the buildings show how difficult this process is in terms of mathematical models formulation. Developing an neural model for residential building air infiltration helps manage better the infiltration process and contribute to a wide application of neural networks for processes in building service systems.

A brief generalisation of these proceedings suggests that science is aiming at and assisting the practice to find an optimal way for the energy systems effectively employed in the market economy to ensure the comfort in premises, which the consumer chooses matching his wishes and possibilities under acceptable conditions from the point of economical, social and environmental view. 